\title{
Comparação da sensibilidade de métodos para a detecção de fungos patogênicos em sementes de aveia branca e preta no Rio Grande do Sul
}

\author{
Mirella Figueiró de Almeida \& Erlei Melo Reis \\ Laboratório de Fitopatologia, Faculdade de Agronomia e Medicina Veterinária, Universidade de Passo Fundo, 99001-970, \\ Passo Fundo, RS, Brasil
}

Autor para correspondência: Erlei Melo Reis, e-mail: erleireis@tpo.com.br

\begin{abstract}
RESUMO
A cultura da aveia, representada pelas espécies Avena sativa L. e Avena strigosa Schreb, é uma das principais alternativas para o cultivo durante o inverno no Sul do Brasil. Os patógenos dessa cultura, como Drechslera avenae causador da helmintosporiose, sobrevivem em sementes e nos restos culturais. Em experimentos conduzidos em laboratório foram testados dois métodos de detecção, incubação em substrato de batata-dextrose-ágar (BDA) e em meio semi-seletivo de Reis, visando selecionar o mais sensível na detecção de $D$. avenae, Alternaria alternata e Bipolaris sorokiniana e quantificar a incidência destes fungos em sementes de aveia produzidas em diferentes municípios do Rio Grande do Sul. O método semi-seletivo de Reis mostrou-se mais sensível na detecção de D. avenae e A. alternata em aveia branca, para B. sorokiniana, o método com BDA foi o mais sensível em aveia branca, não diferindo do seletivo de Reis para aveia preta. A menor e maior incidência de $D$. avenae em sementes de aveia branca variaram de 12 a $76 \%$ e em aveia preta de 4 a $90 \%$, para A. alternata variaram de 3 a $53 \%$ e 2 a $31 \%$ em aveia branca e preta respectivamente e $B$. sorokiniana em aveia branca de 0 a $16 \%$ e 0 a $3 \%$ em preta.
\end{abstract}

Palavras-chave: Drechslera avenae, Alternaria alternata, Bipolaris sorokiniana helmintosporiose, patologia de sementes.

\begin{abstract}
Sensitivity of methods for detection of pathogenic fungi in white and black oat seeds in Rio Grande do Sul state

The oat crop, represented by the species Avena sativa and Avena strigosa, is one of the most important alternatives for agriculture during winter in Southern Brazil. Oat pathogens such as Drechslera avenae, the causal agent of helminthosporiosis, survive in seeds and in crop residues. In experiments conducted in the laboratory two media substrates were tested, potato-dextrose-agar and Reis semi-selective, aiming to select the most sensitive in the detection of $D$. avenae. Two other fungi in seeds were also evaluated, Alternaria alternata and Bipolaris sorokiniana. Another objective of this work was to quantify the incidence of fungi in oat seeds produced in some counties of Rio Grande do Sul state. A total of 38 samples had been plated in gerboxes containing the culture medium and incubated in a climatized chamber. The semi-selective medium was more sensitive in the detection of D. avenae and of A. alternata in white and black oats; on the other hand, for B. sorokiniana, the PDA media was more sensitive in white oats, while for black oats there was no statistical difference. In the quantification of fungi in white and black oat seeds in the various counties, the lowest and highest incidence of $D$. avenae in white oat seeds varied from 12 to $76 \%$ and in black oats from 4 to $90 \%$; for $A$. alternata it varied from 3 to $53 \%$ in white oats and 2 to $31 \%$ in black oats; for $B$. sorokiniana it varied from 0 to $16 \%$ in white oats and 0 to $3 \%$ in black oats.
\end{abstract}

Keywords: Drechslera avenae, Alternaria alternata, Bipolaris sorokiniana helminthosporiosis, seed pathology.

A aveia é uma das principais culturas utilizadas no Sul do Brasil, quando se visa a diversificação na exploração agrícola, e sua área de cultivo vem crescendo continuamente devido à necessidade de alternativas para rotação de culturas (Comissão Brasileira de Pesquisa de Aveia, 2006). A cultura da aveia, representada pelas espécies Avena sativa L. e Avena strigosa Schreb., ocupa grande área cultivada no Sul

Parte da Dissertação de Mestrado do primeiro autor. Universidade de Passo Fundo. Passo Fundo RS. 2008. do Brasil, tornando-se uma das principais alternativas para o cultivo durante o inverno. Um dos fatores que contribuíram para o aumento da área cultivada com aveia, foi a adequação do sistema de cultivo tradicional, em substituição ao trigo ou cevada, na rotação de culturas no inverno. A aveia é a principal cultura alternativa para rotação com demais cereais de inverno, por não ser suscetível aos patógenos agentes causais de manchas foliares e de podridões radiculares (Reis et al., 1999a).

O cultivo da aveia visando à produção de grãos, forragem e adubação verde, estão concentrados no sul do Brasil, especialmente nos estados do Rio Grande do Sul, 
Paraná e Santa Catarina. No Mato Grosso do Sul, São Paulo e Sul de Minas Gerais, o cultivo é destinado à produção de forragem, mostrando aumentos para a produção de grãos (Comissão Brasileira de Pesquisa de Aveia, 2006). O sucesso dos programas de melhoramento e a elevação do potencial dos novos cultivares aumentaram a proporção da aveia dentre os cereais de inverno no sistema de rotação de culturas. No entanto, a importância de algumas doenças fúngicas, como fatores limitantes de rendimento, tem aumentado (Martinelli, 2003). Como conseqüência de seu manejo inadequado à aveia, principalmente aveia preta encontra-se perenizada, na maioria das lavouras do Sul do Brasil. Em especial observou-se um aumento da mancha foliar "helmintosporiose da aveia, causada pelo fungo Drechslera avenae (Eidam) Sharif, estando ela diretamente relacionada com o sistema de plantio direto (Martinelli, 2003).

Os grãos de aveia manchados são um fator limitante para a sua comercialização, tornando o produto escuro e não permitindo seu uso pela indústria alimentícia, tornando-se um problema de grande magnitude ao agronegócio desta cultura (Bocchese et al., 2001). Os objetivos deste trabalho foram comparar a sensibilidade de dois métodos de detecção de D. avenae, Alternaria alternata (Fr.) Keissl. e Bipolaris sorokiniana (Sacc.) Schoemaker utilizando meios de cultura agarizados e quantificar a incidência destes fungos em sementes de aveia branca e preta produzidas no Rio Grande do Sul.

A pesquisa foi conduzida no Laboratório de Fitopatologia da Faculdade de Agronomia e Medicina Veterinária - FAMV da Universidade de Passo Fundo UPF. Amostras de sementes de aveia branca e preta da safra de 2005/06 provenientes de diferentes municípios recebidas no laboratório de Sementes da FAMV da UPF, foram colocadas em gerboxes de acrílico, previamente esterilizados contendo os substratos. Neste procedimento acondicionou-se 100 gerboxes em um saco plástico com volume de $100 \mathrm{~L}$, adicionou-se o agente esterilizante num copo de becker num chumaço de algodão embebido com $50 \mathrm{~mL}$ de formol (Formalina 40). O material permaneceu em câmara aquecida a $40^{\circ} \mathrm{C}$ durante 48 horas e, finalmente mantido o saco de plástico aberto numa capela para liberaração do gás durante 48 horas. Foram utilizadas 10 amostras de aveia branca provenientes dos municípios de Carazinho, Lagoa Vermelha (2), Passo Fundo (5), Sarandi e Vacaria e 28 de aveia preta dos municípios de André da Rocha, Carazinho (2),Chapada, Erechim, Ibiraiaras, Ibirubá, Lagoa Vermelha, Lajeado, Palmeira das Missões, Passo Fundo (3), Sananduva (3), Santo Augusto, São José do Ouro, Sarandi, Selbach, Sertão, Soledade, Tapejara, Tapera, Três Palmeira, Trindade do Sul e Vacaria (2). Os meios de cultura foram preparados de acordo com os protocolos de Reis (1983) e Fernandez (1993).

Meio Semi-Seletivo de Reis-o meio de cultura foi preparado dividindo-se em duas partes: Parte A: consistiu de $15 \mathrm{~g}$ de batata cozida em $700 \mathrm{~mL}$ de água destilada, obtendo-se um caldo de batata que foi colocado em erlenmeyer de 2000 $\mathrm{mL}$, volume final ajustado de $1.000 \mathrm{~mL}$ onde foi adicionado $15 \mathrm{~g}$ de ágar e $2,5 \mathrm{~g}$ de sacarose e autoclavado a $120^{\circ} \mathrm{C}$ por 20 minutos; e parte B: 0,50 g de Sulfato de Estreptomicina, $0,30 \mathrm{~g}$ de Neomicina e $0,30 \mathrm{~g}$ de benomil, sendo que cada produto foi dissolvido em balões volumétricos individuais contendo $100 \mathrm{~mL}$ de água destilada esterilizada. Após autoclavada a parte A foi resfriada a uma temperatura de aproximadamente $45^{\circ} \mathrm{C}$. Em câmara de fluxo laminar as partes A e B foram misturadas e foram adicionados ao meio $5 \mathrm{~mL}$ de botram e $3 \mathrm{~mL}$ de captana. As soluções estoque continham $0,20 \mathrm{~g}$ de botram e $0,133 \mathrm{~g}$ de captam. $100 \mathrm{~mL}^{-1}$ de água destilada esterilizada.

Meio Batata-Dextrose-Ágar (BDA) - o meio de cultura consistiu de $200 \mathrm{~g}$ de batata fatiada cozidas em $500 \mathrm{~mL}$ de água destilada. Em um erlenmeyer de $2000 \mathrm{~mL}$ de capacidade foi adicionado o caldo da batata, $15 \mathrm{~g}$ de ágar e $20 \mathrm{~g}$ de dextrose, ajustado o volume final para $900 \mathrm{~mL}$ e autoclavado a $120^{\circ} \mathrm{C}$ por 20 minutos. Após a autoclavagem o substrato resfriado até atingir a temperatura de aproximadamente $45^{\circ} \mathrm{C}$. Em câmara de fluxo laminar foi dissolvido $0,2 \mathrm{~g}$ sulfato de estreptomicina em $100 \mathrm{~mL}$ de água destilada esterilizada que foi adicionado ao meio BDA (Fernandez, 1993).

As sementes foram desinfestadas em hipoclorito de sódio a $1 \%$ por dois minutos antes do plaqueamento, após foram lavadas três vezes em água destilada para remover o resíduo do hipoclorito. Foram plaqueadas, com auxílio de pinça previamente flambada, um total de 400 sementes de cada amostra. As sementes foram incubadas a $25 \pm 2^{\circ} \mathrm{C} \mathrm{em}$ câmara climatizada com fotoperíodo de 12 horas durante 12 dias e sete dias respectivamente para o meio seletivo e BDA.

A incidência dos fungos nas sementes foi determinada sete dias após a incubação no meio BDA e 12 dias no meio semi-seletivo. A quantificação da incidência dos fungos foi feita sob microscópio estereoscópico (50X) considerando-se infectada a semente com presença de conidióforos e conídios do fungo alvo. O delineamento experimental foi de blocos casualizados e a unidade experimental constituída por quatro gerboxes contendo 25 sementes cada (100 sementes por repetição). Sendo comparados dois tratamentos, os dados foram submetidos apenas à análise de variância para a comparação das médias.

O meio mais sensível na detecção de $D$. avenae e A. alternata foi o meio semi-seletivo de Reis tanto para aveia branca como para preta; já para $B$. sorokiniana, o meio BDA foi o mais sensível em aveia branca, sendo que para aveia preta não houve diferença estatística entre os meios (Figura $1 \mathrm{~A}-\mathrm{B}$ ). Em teste paralelo se demonstrou que no meio semi-seletivo não é necessária a desinfestação das sementes devido à composição do meio permitir somente o desenvolvimento de membros da família Dematiaceae. 

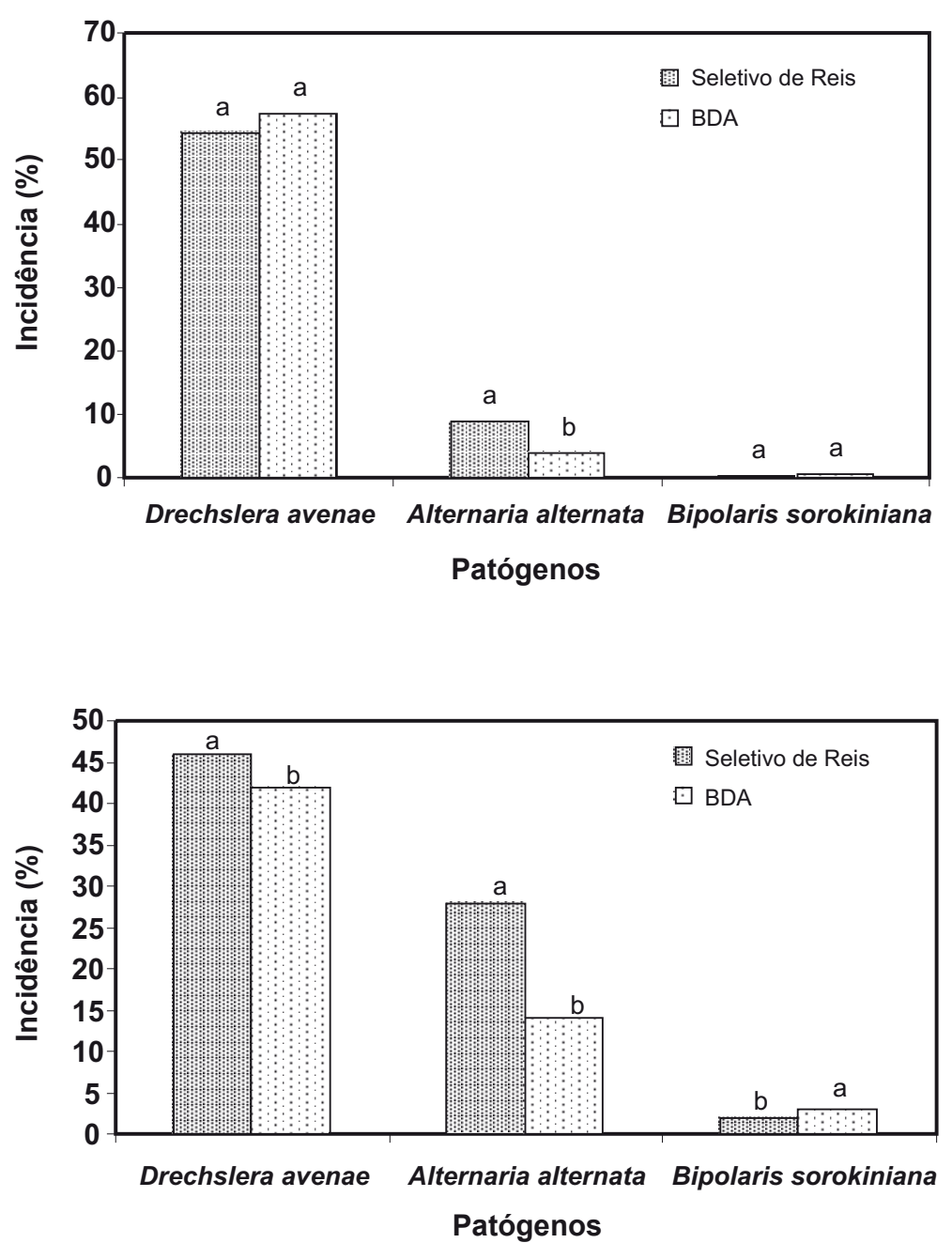

FIGURA 1 - Comparação da sensibilidade de meios de cultura para detecção de Drechslera avenae, Alternaria alternata e Bipolaris sorokiniana em sementes de aveia A. aveia branca C.V. $6,30 \%, 8,61 \%$ e $13,75 \%$ respectivamente; B. aveia preta C.V. $=6,53 \%$, $15,16 \%$ e $23,53 \%$ respectivamente. Médias seguidas de mesma letra não diferem entre si pelo $\mathrm{F}$ teste.
Este fato contribui para reduzir o uso de material e dar precisão na identificação dos fungos. Segundo Barba et al. (2002), o desempenho do meio BDA pode ser inferior quando a semente não for desinfestada, pois a presença de contaminantes de crescimento rápido, como Trichoderma spp., Rhizopus spp. e Fusarium spp. podem, em pouco tempo, cobrir completamente o gerbox, dificultando a identificação e detecção do fungo alvo.

O presente trabalho vem corroborar com trabalhos de comparação de métodos de detecção de fungos em sementes de cereais de inverno feitos por Lângaro (1998), Reis et al. (1999b), Barba et al. (2002), nos quais o meio semi-seletivo de Reis apresentou-se mais sensível. Os métodos que apresentaram-se mais sensíveis na detecção de $D$. avenae de um total de 10 métodos comparados com um padrão (meio semi-seletivo de Reis) foram os métodos osmótico, semi-seletivo de Reis e aquecimento, resultando em incidência detectada de $61,50 \%, 49,25 \%$ e $41,75 \%$ respectivamente (Lângaro, 1998). Em estudo realizado por Reis et al. (1999b) o meio de Reis foi mais sensível na detecção de $D$. avenae em sementes de aveia, $B$. sorokiniana e Drechslera tritici-repentis em sementes de trigo e Drechslera teres em sementes de cevada. Segundo Barba et al. (2002), foram testados sete métodos para detecção de $B$. sorokiniana que apresentou a maior incidência também no meio semi-seletivo de Reis com $43 \%$ de incidência em sementes de cevada.

$\mathrm{O}$ aspecto positivo, que deve ser salientado em relação aos métodos de detecção, é que o meio semiseletivo de Reis mostrou-se um método preciso e seguro de detecção de fungos assexuados pigmentados (dematiaceae). Além de apresentar-se mais sensível, apesar de permanecer incubado por um período de tempo maior que o meio BDA, também permitiu o desenvolvimento somente dos fungos alvo do estudo. A maior incidência de $D$. avenae, em sementes de aveia branca e preta foi de 76 e $90 \%$ nos municípios de Passo Fundo e São José do Ouro respectivamente e a menor incidência foi detectada nos municípios de Passo Fundo com $12 \%$ e Tapera com $4 \%$ em sementes de aveia branca e preta respectivamente (Figuras 2 e 3 ). Em levantamento feito por Reis \& Soares (1995) em sementes de aveia 


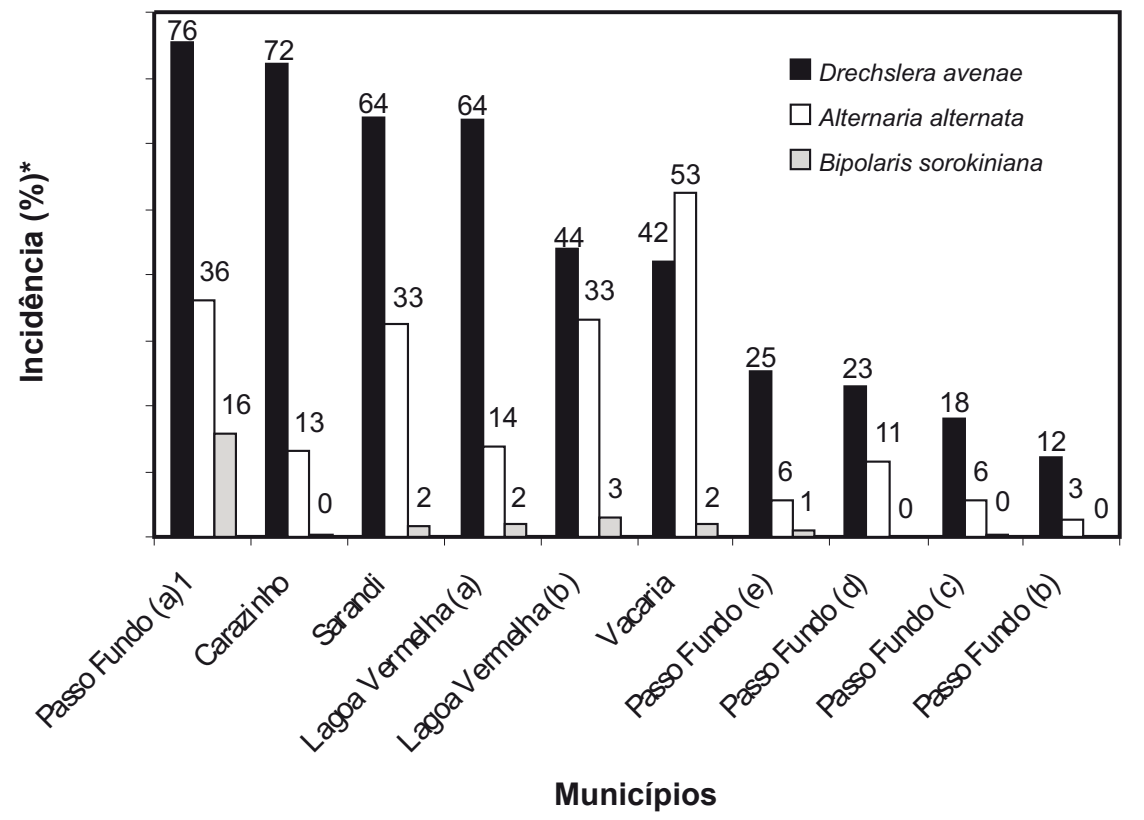

FIGURA 2 - Incidência de fungos em sementes de aveia branca em diferentes municípios do Rio Grande do Sul. $\left({ }^{1}\right)=$ As letras entre parênteses referem-se a diferentes localidades no mesmo município.

(*) = Média dos meios de cultura.

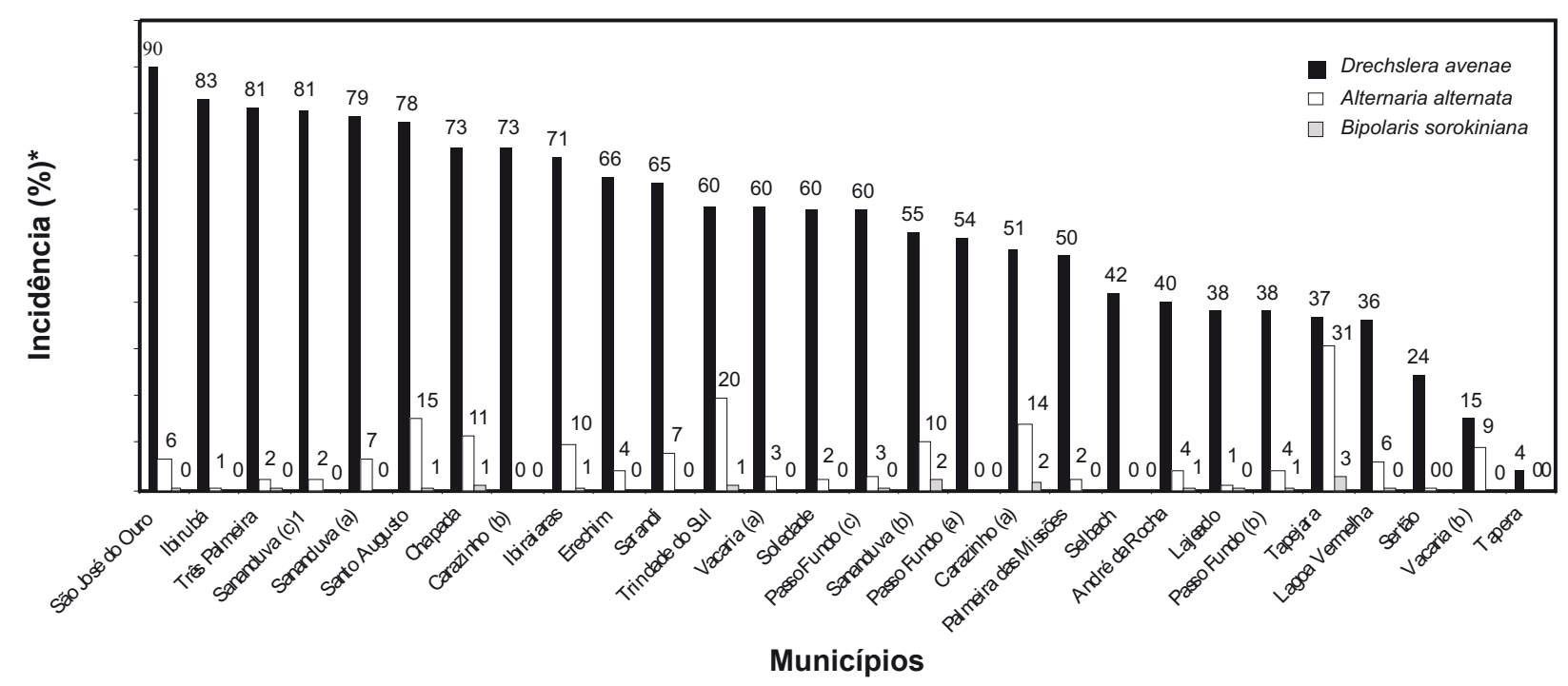

FIGURA 3 - Incidência de fungos em sementes de aveia preta em diferentes municípios do Rio Grande do Sul. ( $\left.{ }^{1}\right)=$ As letras entre parênteses referem-se a diferentes localidades no mesmo município. $(*)=$ Média dos meios de cultura.

branca proveniente de diferentes municípios dos estados do Rio Grande do Sul, Paraná e Mato Grosso do Sul, a incidência de $D$. avenae variou de 4,25 a $70 \%$. Em pesquisa desenvolvida na Argentina, a incidência de $D$. avenae em sementes de aveia branca variou de 0 a $52 \%$ de um total de 24 amostras avaliadas provenientes de diferentes localidades (Carmona et al., 2004). O presente trabalho mostra que o $D$. avenae está amplamente distribuído em sementes/grãos onde aveia é cultivada o que compromete sua qualidade na comercialização para fins industriais. O meio seletivo apresenta maior sensibilidade e economia de material.

\section{AGRADECIMENTOS}

Os autores registram agradecimentos a Coordenação de Aperfeiçoamento de Pessoal de Nível Superior - CAPES pela concessão de bolsas de estudo. 


\section{REFERÊNCIAS BIBLIOGRÁFICAS}

Barba JT, Reis EM, Forcelini AC (2002) Comparação de métodos para detecção de Bipolaris sorokiniana em sementes de cevada. Fitopatologia Brasileira 27:389-394.

Bocchese CAC, Martinelli JA, Matsumura ATS, Federizzi LC, Dresch LF, Tellier M (2001) Especificidade de Pyrenophora avenae aos tecidos da semente de Avena sativa e sua atividade enzimática. Fitopatologia Brasileira 26:180-184.

Carmona MA, Zweegman J, Reis EM (2004) Detection and transmission of Drechslera avenae from oat seed. Fitopatologia Brasileira 29:319-321.

Comissão Brasileira de Pesquisa de Aveia (2006) Indicações técnicas para cultura aveia: grãos e forrageiras. Passo Fundo RS. Universidade de Passo Fundo.

Fernandez MR (1993) Manual para laboratório de fitopatologia. Documentos 6. Passo Fundo RS. EMBRAPA Trigo.
Lângaro NC (1998) Detecção, transmissão e controle de Drechslera avenae em sementes de aveia branca. Dissertação de Mestrado. Universidade de Passo Fundo. Passo Fundo RS.

Martinelli JA (2003) Manejo integrado de doenças da aveia. Fitopatologia Brasileira 28(Supl.):98-101.

Reis EM (1983) Selective medium for isolating Cochliobolus sativus from soil. Plant Disease 67:68-70.

Reis EM, Soares RM (1995) Levantamento, transmissão e controle de fungos patogênicos associados a sementes de aveia. Resultados experimentais, XV Reunião da Comissão Sul-Brasileira de Pesquisa de Aveia. Entre Rios, Guarapuava PR. pp. 257-260.

Reis EM, Blum MMC, Casa RT (1999a) Doenças da aveia: Helmintosporiose. São Paulo SP. Editora Centralgraph Gráfica.

Reis EM, Reis AC, Casa RT, Blum MMC (1999b) Comparison of methods to detect leaf and head blighting fungi in small grain seeds. Summa Phytopathologica 25:364-367.

TPP 8013 - 26 Janeiro 2009 - Aceito 30 Junho 2009 Editor de Seção: Jose da Cruz Machado 